\section{Questión}

Periodismo / Comunicación ISSN 1669-6581
- Av. $44 \mathrm{~N}^{\circ} 676,1^{\circ}$ piso

CP 1900 - La Plata - Argentina

(i) www.perio.unlp.edu.ar/question

Preguntas para contar lo que pasa

Mariana Chiesa Mateos - Rodolfo Luna Almeida

https://doi.org/10.24215/16696581e398

\title{
Preguntas para contar lo que pasa
}

\section{Questions to tell what's going on}

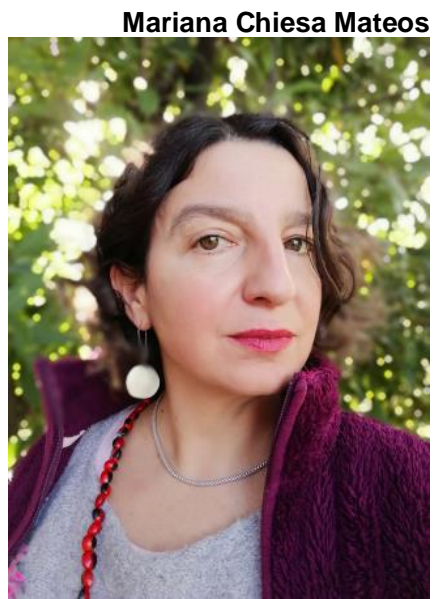

Estudió grabado en la Facultad de Bellas Artes, UNLP, La Plata donde nació. Aprendió historieta con Alberto Breccia. Obtuvo una beca del Fondo Nacional de la Artes. Aprendió litografía en la Scuola Llotja dell'Arte del Libro de Barcelona, ciudad donde vivió diez años. Desde el 2008 vive cerca de Bolonia, Italia, donde nació su hija. Entre sus libros, que nunca encontraron editor en la Argentina: "No hay tiempo para jugar". Relatos de niños trabajadores, Sandra Arenal/Mariana Chiesa, Ed. Media Vaca, Valencia, España, 2004. Reeditado en Italia por Zoolibri y ARCl, 2007 y en México por la SEP (Secretaría de Educación Pública); "Migrando", Ed. Orecchio Acerbo y Amnesty International, Roma,

2010, editado también en Francia, Portugal y México; "Quasi ninna quasi nanna", Ed. Orecchio Acerbo, 2013. Roma; "Cantico di fratello Sole”, Francesco D’Assisi, Ed. Orecchio Acerbo, Else, Roma. Participó en numerosas exposiciones y recibió reconocimientos por su trabajo, entre los últimos: "Furia y Filo", exposición individual, obra gráfica y textil, Galeria

Portanova 12, Bologna, Italia, 2019; Primer premio a la ilustración latinoamericana, Universidad de Palermo, Buenos

Aires, 2014. 
Rodolfo Luna Almeida

Nació en La Plata, el 1 de enero de 1954. Es padre de cuatro hijos y abuelo de cinco nietos. Estudió en el Bachillerato de Bellas Artes y en el Colegio Nacional de la UNLP. Diseñador gráfico, trabajó en editoriales, diarios y publicaciones en la ciudad de Buenos Aires entre mediados de los '70 y 2019, en el diseño, diagramación e ilustración de periódicos, revistas

y libros. Entre ellos, La Razón, Nuevo Sur, Clarín, Editorial Atlántida, Editorial Estrada, Editorial Planeta y Fundación Antorchas. Diseñó periódicos de izquierda y publicaciones sindicales. Integró la redacción del periódico Madres de Plaza de Mayo entre 1985 y 2000. En 2001 editó y dirigió el mensuario Villa Elisa y su gente, de la localidad bonaerense homónima, donde vive. Se jubiló como trabajador de prensa en la Agencia Nacional de Noticias Télam, en la que trabajó desde 2004 hasta 2019. En 2017 salió su primera novela, "Marinka, una rusa niña vasca", publicada por Planeta y reeditada en 2018. Participa actualmente de los colectivos Vecinos de Villa Elisa por la Memoria, la Verdad y la Justicia, y Los Cordelistas, que editan la publicación La Trama, historias de vecinos, distinguida en dos oportunidades por el Fondo

Nacional de las Artes. 
La idea de un trabajo en común surgió de una comunicación telefónica con Mariana cuando ella ya estaba en cuarentena en Italia y aquí recién había un par de casos importados. Nos propusimos encontrar la forma de contar lo que pasaba, en principio a través de una historia gráfica, y lo primero que ilustró Mariana, con personajes vestidos a la usanza de los médicos medievales en la peste negra, fue una serie de preguntas que me formulé al principio de la pandemia:

- ¿Hay barbijos contra el odio?

- ¿Qué nos protege de la estupidez?

- ¿En qué hospital se tratan las injusticias?

- ¿Cómo prevenirnos de la hipocresía?

- ¿Cuándo sale la vacuna contra el miedo?

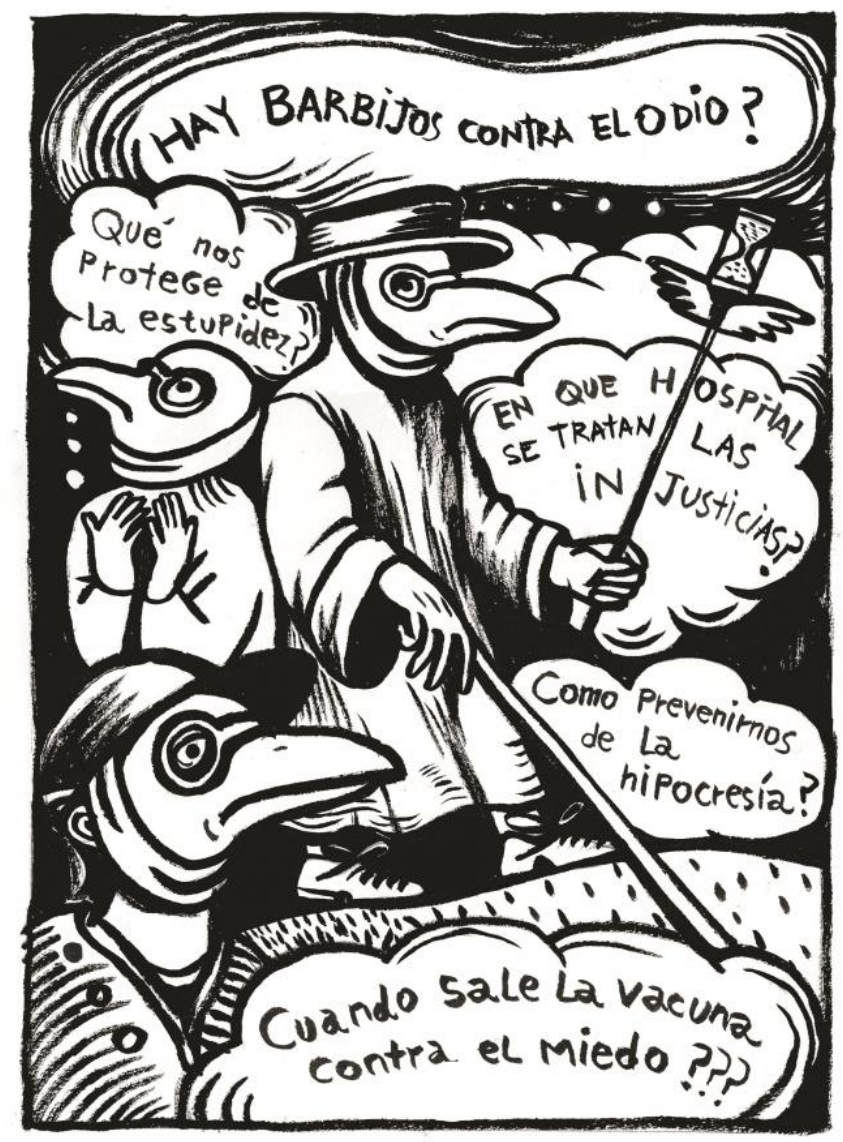

